\title{
A phosphodiesterase 4-controlled switch between memory extinction and strengthening in the hippocampus
}

\author{
Rafael Roesler 1,2,3*, Gustavo K. Reolon 1,2,3, Natasha Maurmann 1,2,3, Gilberto Schwartsmann ${ }^{2,3,4}$, \\ Nadja Schröder ${ }^{3,5}$, Olavo B. Amaral ${ }^{6}$, Samira Valvassori ${ }^{3,7}$ and João Quevedo ${ }^{3,7,8}$ \\ ${ }^{1}$ Laboratory of Neuropharmacology and Neural Tumor Biology, Department of Pharmacology, Institute for Basic Health Sciences, Federal University of Rio \\ Grande do Sul, Porto Alegre, Brazil \\ ${ }^{2}$ Cancer Research Laboratory, University Hospital Research Center (CPE-HCPA), Federal University of Rio Grande do Sul, Porto Alegre, Brazil \\ ${ }^{3}$ National Institute for Translational Medicine (INCT-TM), Porto Alegre, Brazil \\ ${ }^{4}$ Department of Internal Medicine, School of Medicine, Federal University of Rio Grande do Sul, Porto Alegre, Brazil \\ ${ }^{5}$ Neurobiology and Developmental Biology Laboratory, Faculty of Biosciences, Pontifical Catholic University, Porto Alegre, Brazil \\ ${ }^{6}$ Leopoldo de Meis Institute of Medical Biochemistry, Federal University of Rio de Janeiro, Rio de Janeiro, Brazil \\ ${ }^{7}$ Laboratory of Neurosciences, Graduate Program in Health Sciences, Academic Unit of Health Sciences, University of Southern Santa Catarina (UNESC), \\ Criciúma, Brazil \\ ${ }^{8}$ Center for Experimental Models in Psychiatry, Department of Psychiatry and Behavioral Sciences, The University of Texas Medical School at Houston, \\ Houston, TX, USA
}

\section{Edited by:}

Christa Mclntyre, University of Texas, USA

\section{Reviewed by:}

Yasuyuki Ishikawa, Maebashi Institute of Technology, Japan

Silvia Middei, Consiglio Nazionale delle Ricerche, Italy

*Correspondence:

Rafael Roesler, Laboratory of Neuropharmacology and Neural Tumor Biology, Department of Pharmacology, Institute for Basic Health Sciences, Federal University of Rio Grande do Sul, Rua Sarmento Leite, 500 (ICBS, Campus Centro/UFRGS), Sala 202, 90050-170-Porto Alegre, Brazil e-mail: rafael.roesler@pq.cnpq.br
Established fear-related memories can undergo phenomena such as extinction or reconsolidation when recalled. Extinction probably involves the creation of a new, competing memory trace that decreases fear expression, whereas reconsolidation can mediate memory maintenance, updating, or strengthening. The factors determining whether retrieval will initiate extinction, reconsolidation, or neither of these two processes include training intensity, duration of the retrieval session, and age of the memory. However, previous studies have not shown that the same behavioral protocol can be used to induce either extinction or reconsolidation and strengthening, depending on the pharmacological intervention used. Here we show that, within an experiment that leads to extinction in control rats, memory can be strengthened if rolipram, a selective inhibitor of phosphodiesterase type 4 (PDE4), is administered into the dorsal hippocampus immediately after retrieval. The memory-enhancing effect of rolipram lasted for at least 1 week, was blocked by the protein synthesis inhibitor anisomycin, and did not occur when drug administration was not paired with retrieval. These findings indicate that the behavioral outcome of memory retrieval can be pharmacologically switched from extinction to strengthening. The CAMP/protein kinase A (PKA) signaling pathway might be a crucial mechanism determining the fate of memories after recall.

Keywords: phosphodiesterase 4, rolipram, extinction, reconsolidation, hippocampus, inhibitory avoidance, fear memory

\section{INTRODUCTION}

Newly formed memory traces become increasingly resistant to disruption or enhancement by different types of interference, through the process known as consolidation (McGaugh, 2000). However, the retrieval of a previously consolidated memory can lead to phenomena such as extinction, which is likely based on the formation of a new memory that weakens the expression of the original learning (Bouton and Bolles, 1979; Quirk and Mueller, 2008), and reconsolidation, a process involving labilization followed by a new phase of stabilization, that may serve to maintain, update, or strengthen the memory trace (Nader et al., 2000; Sara, 2000a; Alberini, 2011). Extinction and reconsolidation are usually viewed as two opposing and possibly competing processes triggered by retrieval, resulting in long-lasting modifications of the original memory trace, or at least of its behavioral expression.
The factors determining whether extinction, reconsolidation accompanied by strengthening, or neither of these processes will be initiated by retrieval remain poorly understood. Studies have found that manipulations of training intensity, retrieval duration, and age of the memory can be used to guide memory retrieval towards extinction or reconsolidation. For example, the use of longer retrieval sessions led to extinction, while a shorter exposure to the learning environment during retrieval induces labilization and sensitivity to drug interference (Pedreira and Maldonado, 2003; Suzuki et al., 2004; Lee et al., 2006). In addition, retrieval more likely results in reconsolidation-mediated strengthening when the original memory is younger or more robust (Eisenberg et al., 2003; Inda et al., 2011). Thus, some of the behavioral training and testing conditions that allow for the discrimination between extinction and reconsolidation have been characterized. 
However, previous studies have not shown whether purely pharmacological, biochemical, or molecular factors can act as switches determining the occurrence of extinction or reconsolidation upon retrieval. Here we investigated the effect of postretrieval phosphodiesterase type 4 (PDE4) inhibition in the dorsal hippocampus on memory retention. The original aim of this study was to examine the role of PDE4 in extinction, and our initial hypothesis was that rolipram could accelerate extinction of inhibitory avoidance (IA). We chose rolipram as a selective PDE4 inhibitor known to enhance hippocampal long-term potentiation (LTP) and memory in different models (Barad et al., 1998; Tully et al., 2003). Surprisingly, we found that, under experimental conditions in which retrieval normally leads to extinction, this outcome can be switched to memory strengthening by a single intrahippocampal infusion of rolipram. To our knowledge, this finding provides the first evidence that whether retrieval will lead to extinction or strengthening (possibly mediated by reconsolidation) can be influenced by manipulating cell signaling mechanisms in the brain.

\section{METHODS}

\section{ANIMALS}

Adult male Wistar rats (310-400 g of weight, around 90 days of age at time of surgery) were obtained from the institutional breeding facility (CREAL, ICBS, UFRGS, Porto Alegre, Brazil) and the State Health Science Research Foundation (FEPPS-RS, Porto Alegre, Brazil). Animals were housed five per cage in plastic cages with sawdust bedding, and maintained on a $12 \mathrm{~h}$ light/dark cycle at a room temperature of $22 \pm 1 \mathrm{C}$. The rats were allowed ad libitum access to standardized pellet food and water. All experiments took place between 9 AM and 6 PM. All experimental procedures were performed in accordance with the National Institutes of Health (NIH) Guide for the Care and Use of Laboratory Animals and were approved by the institutional animal care committee (CEUA-HCPA 05-519).

\section{SURGERY}

Animals were implanted under anesthesia with ketamine $(75 \mathrm{mg} / \mathrm{kg})$ and xylazine $(25 \mathrm{mg} / \mathrm{kg})$ with bilateral $14-\mathrm{mm}$ or 9.0- $\mathrm{mm}, 23$-gauge guide cannulae aimed $1.0 \mathrm{~mm}$ above the CA1 area of the dorsal hippocampus, as described in previous studies (Roesler et al., 2006; Jobim et al., 2012). Coordinates anteroposterior, $-4.3 \mathrm{~mm}$ from bregma; mediolateral, $\pm 3.0 \mathrm{~mm}$ from bregma; ventral, $-2.0 \mathrm{~mm}$ from skull surface) were obtained from the atlas of Paxinos and Watson (2007). Animals were allowed to recover for at least 7 days after surgery.

\section{DRUGS AND INFUSION PROCEDURES}

The general procedures for intra-hippocampal infusions were as described in previous reports (Quevedo et al., 1999; Luft et al., 2006; Roesler et al., 2006). At the time of infusion, a 30-gauge infusion needle was fitted into the guide cannula. The tip of the infusion needle protruded $1.0 \mathrm{~mm}$ beyond the guide cannula and was aimed at the CA1 area of the dorsal hippocampus. The animals received, via the infusion cannula, a bilateral $0.8 \mu \mathrm{l}$ infusion of vehicle (20\% dimethylsulfoxide, DMSO, in saline), the PDE4 inhibitor rolipram $(7.5 \mu \mathrm{g}$ /side dissolved in vehicle;
Sigma-Aldrich, St. Louis, USA), the protein synthesis inhibitor anisomycin (80.0 $\mu \mathrm{g} /$ side dissolved in vehicle; Sigma-Aldrich, St. Louis, USA), or rolipram combined with anisomycin at the doses described above. Drug doses were chosen on the basis of previous studies (Quevedo et al., 1999; Vianna et al., 2001; Luft et al., 2006; Werenicz et al., 2012). Drug or vehicle was infused over a 30-s period. Solutions were freshly prepared before each experiment.

In different experiments, intra-hippocampal infusions were given immediately after the first retrieval session (which also served as extinction training), $1 \mathrm{~h}$ after retrieval (delayed infusion controls), $24 \mathrm{~h}$ after training in the absence of retrieval (no retrieval controls), or immediately after training.

\section{INHIBITORY AVOIDANCE}

We used the single-trial step-down IA task as an established model of fear memory. In step-down IA training, animals learn to associate a location in the training apparatus (a grid floor) with an aversive stimulus (footshock). The general procedures for IA behavioral training and retention tests have been described in previous reports (Quevedo et al., 1999; Luft et al., 2006; Jobim et al., 2012). The IA apparatus was a $50 \times 25 \times 25-\mathrm{cm}$ acrylic box (Albarsch, Porto Alegre, Brazil) whose floor consisted of parallel caliber stainless steel bars (1 $\mathrm{mm}$ diameter) spaced $1 \mathrm{~cm}$ apart. A $7-\mathrm{cm}$ wide, $2.5-\mathrm{cm}$ high platform was placed on the floor of the box against the left wall.

On training trials, rats were placed on the platform and their latency to step down on the grid with all four paws was measured with a digital chronometer connected to the box control unit. Immediately after stepping down on the grid, rats received a mild footshock $(0.5-\mathrm{mA}, 2.0-\mathrm{s})$ and were removed from the apparatus immediately afterwards. Retention test trials (retrieval sessions also serving as extinction training trials) took place at different time points after training by placing the rats on the platform and recording their latencies to step down. No footshock was presented during retention test trials. In trials in which post-retrieval drug infusions were given, rats that did not step down to the grid floor within $180 \mathrm{~s}$ were led by the experimenter to step down on the grid floor for $3 \mathrm{~s}$. Step-down latencies on the retention test trial (maximum 180 s) were used as a measure of IA memory retention. In some of the experiments, rats showing extinction were given a 0.2 $\mathrm{mA}, 2.0$-s reminder footshock at the end of the series of testing sessions (Tronel and Alberini, 2007), followed by an additional retention test $24 \mathrm{~h}$ later. It should be mentioned that this is a collaborative experiment in which two identical IA training apparatuses in two different laboratories were used for different experiments.

\section{HISTOLOGY}

Twenty-four to $72 \mathrm{~h}$ after behavioral testing, a $0.5-\mu \mathrm{l}$ infusion of a $4 \%$ methylene blue solution was given into the dorsal hippocampus. Rats were sacrificed by decapitation 15 min later, and their brains were removed and stored in 10\% formalin for at least $72 \mathrm{~h}$. The brains were sectioned and examined for cannulae placement in the hippocampus. The extension of the methylene blue dye was taken as indicative of diffusion of the drugs given to each rat. 
Animals included in the final analysis (146 rats) had bilaterally placed cannula in the intended sites. Infusion placements into the dorsal hippocampus, as revealed by the diffusion of methylene blue, was similar to those described in previous reports (Quevedo et al., 1999; Roesler et al., 2006, 2009; Jobim et al., 2012; data not shown).

\section{STATISTICS}

Data are shown as mean \pm S.E.M. retention test latencies to step-down (s). Comparisons of training and retention test stepdown latencies between groups were performed using KruskalWallis analysis of variance followed by Mann-Whitney $U$-tests, two-tailed, when appropriate. Comparisons between behavioral sessions within the same group were made using Friedman tests. Nonparametric tests were chosen because of the ceiling cutoff imposed to retention test latencies (Quevedo et al., 1999; Vianna et al., 2001; Luft et al., 2006; Roesler et al., 2006; Jobim et al., 2012). In all comparisons, $P<0.05$ was considered to indicate statistical significance.

\section{RESULTS}

\section{ADMINISTRATION OF ROLIPRAM INTO THE DORSAL HIPPOCAMPUS AFTER RETRIEVAL SWITCHES MEMORY FROM EXTINCTION TO STRENGTHENING}

In the first experiment, we examined the effect of an intrahippocampal administration of rolipram immediately after IA memory retrieval, using a protocol that induces extinction in control rats (Vianna et al., 2001). The experimental design is shown in Figure 1A. Rats were trained in IA and underwent a retrieval session (Test 1, which also acted as extinction training) $24 \mathrm{~h}$ later. Immediately after retrieval, animals were infused with vehicle $(N=9)$, rolipram $(N=10)$, anisomycin $(N=9)$, or rolipram combined with anisomycin $(N=10)$. Animals were tested again $48 \mathrm{~h}$ (Test 2) and $72 \mathrm{~h}$ (Test 3) after Test 1. Rats infused with vehicle also received a mild 2.0-s reminder footshock (0.2 mA) immediately upon stepping down on Test 3, and were given an additional test trial $24 \mathrm{~h}$ after Test 3 ("Reinstatement"), as a procedure used to confirm that the decrease in latencies across trials was due to extinction (Tronel and Alberini, 2007).

Results are shown in Figure 1B. A Kruskal-Wallis analysis of variance showed significant differences among groups in Test 3 $(H=17.3, \mathrm{df}=3, P<0.01)$, but not in any other behavioral session (Training, $H=2.3$, $\mathrm{df}=3, P=0.52$; Test $1, H=$ 2.60, $\mathrm{df}=3, P=0.46$; Test $2, H=4.3$, $\mathrm{df}=3, P=0.23)$. Further analysis with Mann-Whitney tests showed that rats given rolipram or anisomycin $(P s<0.01)$, or rolipram combined with anisomycin $(P<0.05)$ had latencies in Test 3 that were significantly higher than those in control rats given vehicle. Rats infused with rolipram alone had higher Test 3 latencies compared to rats given anisomycin or rolipram combined with anisomycin $(P s<0.05)$. In control rats given vehicle, retention test latencies progressively declined across test trials, indicating memory extinction. A Friedman test showed a significant decrease in latencies across test trials $(H=13.8, \mathrm{df}=2, P<0.01)$. Stepdown latencies in this group went back to the levels observed in Test 1 in the "Reinstatement" test trial following a reminder

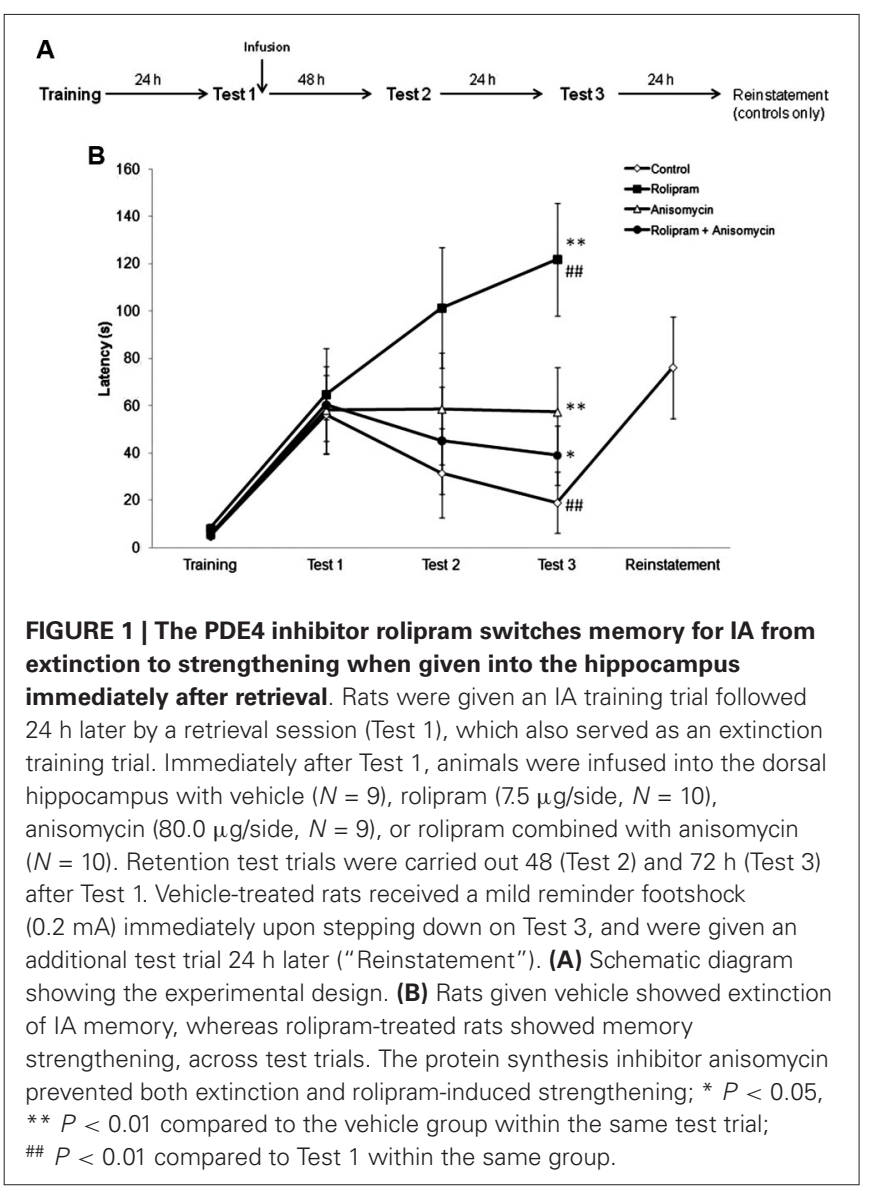

shock, consistent with what would be expected for memory extinction. In contrast, rats infused with rolipram showed a progressive enhancement of IA retention across test trials (comparison among all three test trials using a Friedman test, $H$ $=9.5, \mathrm{df}=2, P<0.01)$. There were no differences between test trials within the groups treated with either anisomycin or rolipram combined with anisomycin (comparison among all three test trials using a Friedman test, anisomycin, $H=1.4$, $\mathrm{df}=2, P=0.49$; rolipram plus anisomycin, $H=4.2, \mathrm{df}=2$, $P=0.12$ ).

These results indicate that (1) in rats trained and tested in a protocol that induces extinction, intrahippocampal rolipram caused memory strengthening rather than extinction to occur after retrieval, and (2) blocking protein synthesis in the dorsal hippocampus prevented both extinction in vehicle-treated rats and the rolipram-induced retention strengthening in animals receiving the drug.

\section{MEMORY ENHANCEMENT BY POST-RETRIEVAL ADMINISTRATION OF ROLIPRAM REQUIRES RECALL}

The second experiment was a "no retrieval control" in which we verified whether retrieval was necessary for the memory facilitation induced by rolipram. Rats were infused with vehicle $(N=$ $13)$, rolipram $(N=12)$, anisomycin $(N=7)$, or anisomycin plus rolipram $(N=9), 24 \mathrm{~h}$ after training in the absence of a retrieval 


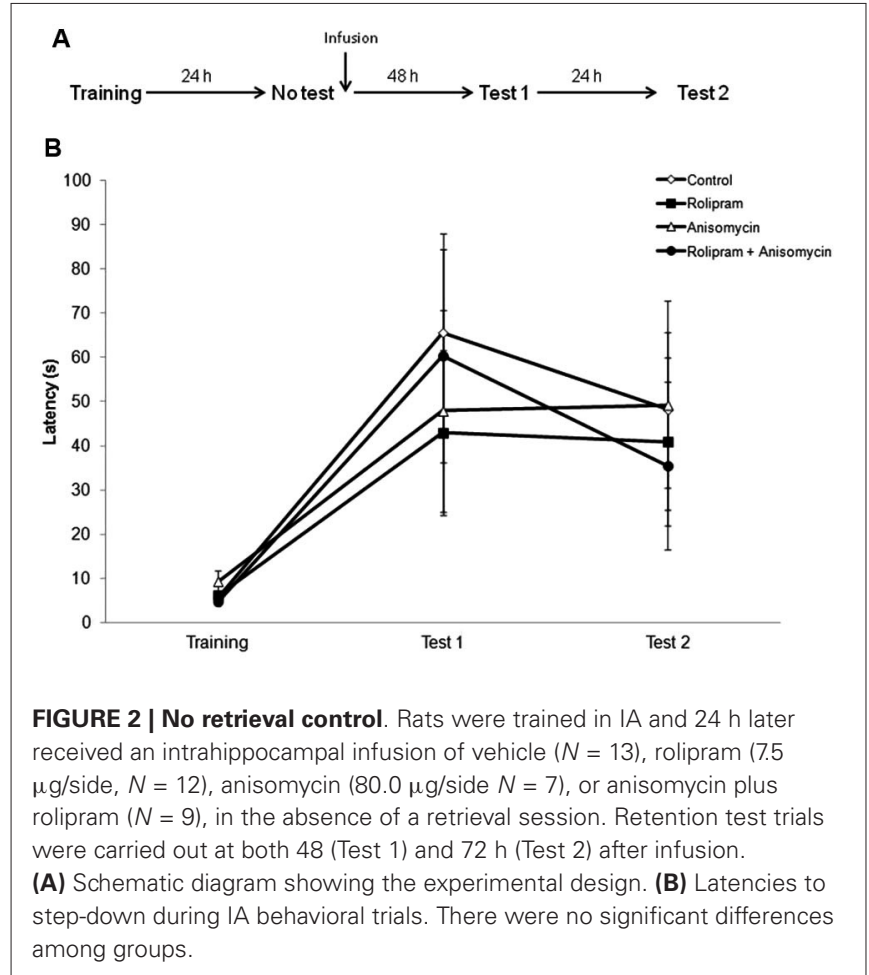

trial (Figure 2A). Rats were tested for retention at both $48 \mathrm{~h}$ (Test 1) and $72 \mathrm{~h}$ (Test 2) after infusion. There were no significant differences among groups (Kruskal-Wallis test, Training, $H=2.9$, $\mathrm{df}=3, P=0.41$; Test $1, H=1.0, \mathrm{df}=3, P=0.80$; Test $2, H=2.0$, $\mathrm{df}=3, P=0.56$; Figure $2 \mathrm{~B}$ ). These results confirm that the drug infusion needs to be paired with retrieval in order for rolipram to enhance memory.

\section{DELAYED POST-RETRIEVAL ADMINISTRATION OF ROLIPRAM INTO THE HIPPOCAMPUS DOES NOT AFFECT MEMORY}

Rolipram had no effect when the intrahippocampal infusion was given $1 \mathrm{~h}$ after retrieval measured at Test 1 ("delayed infusion control"), indicating that PDE4 inhibition can modulate memory strengthening specifically at an early time period after retrieval (Figure 3). Rats were trained and tested as in the first experiment. Mann-Whitney tests showed no significant differences between groups (Training, $P=0.88$; Test $1, P=0.72$; Test $2, P=0.72$; Test $3, P=0.42 ; N=8$ rats per group).

\section{THE MEMORY-ENHANCING EFFECT OF INTRAHIPPOCAMPAL ROLIPRAM GIVEN AFTER RETRIEVAL LASTS FOR AT LEAST 1 WEEK}

In order to examine the persistence of the memory-enhancing effect of post-retrieval rolipram, rats were trained as before and tested at $24 \mathrm{~h}$ (Test 1), $72 \mathrm{~h}$ (Test 2), $96 \mathrm{~h}$ (Test 3), and 7 days (Test 4$)$ later. Vehicle $(N=10)$ or rolipram $(N=9)$ was infused immediately after Test 1 (Figure 4A). Mann-Whitney tests showed significant differences between groups in Test 3 $(P<0.05)$ and Test $4(P<0.01)$, but not in Training $(P=$ $0.97)$, Test $1(P=0.55)$, or Test $2(P=0.13)$. Control rats, but not rats given rolipram, showed a significant decrease in

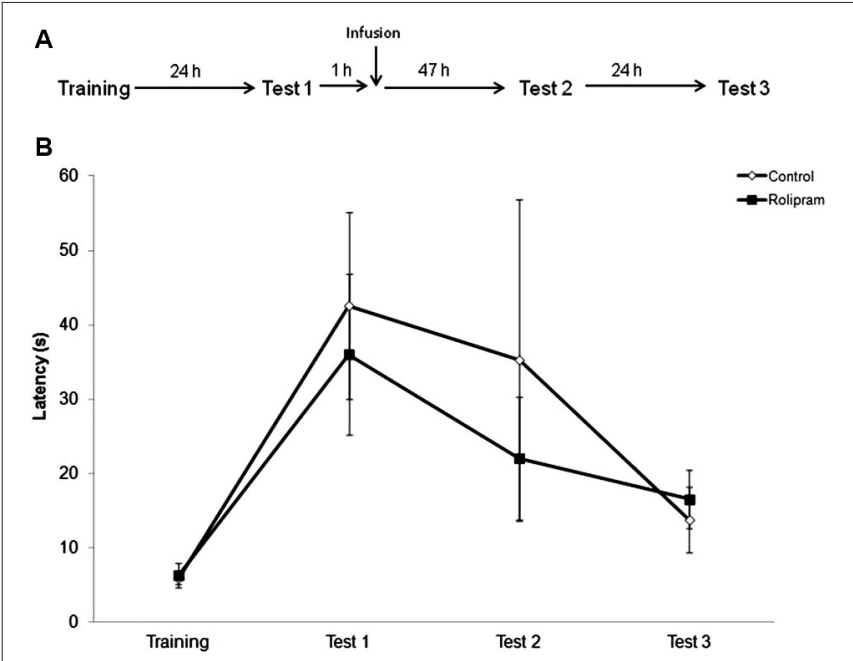

FIGURE 3 | Delayed infusion control. Rats were given an IA training trial followed $24 \mathrm{~h}$ later by a retrieval/extinction session (Test 1). $1 \mathrm{~h}$ after Test 1 animals were infused into the dorsal hippocampus with vehicle or rolipram (7.5 $\mu \mathrm{g} / \mathrm{side}, N=8$ rats per group). Retention test trials were carried out 48 (Test 2) and $72 \mathrm{~h}$ (Test 3) later. (A) Schematic diagram showing the experimental design. (B) Latencies to step-down during IA behavioral trials. There were no significant differences among groups.

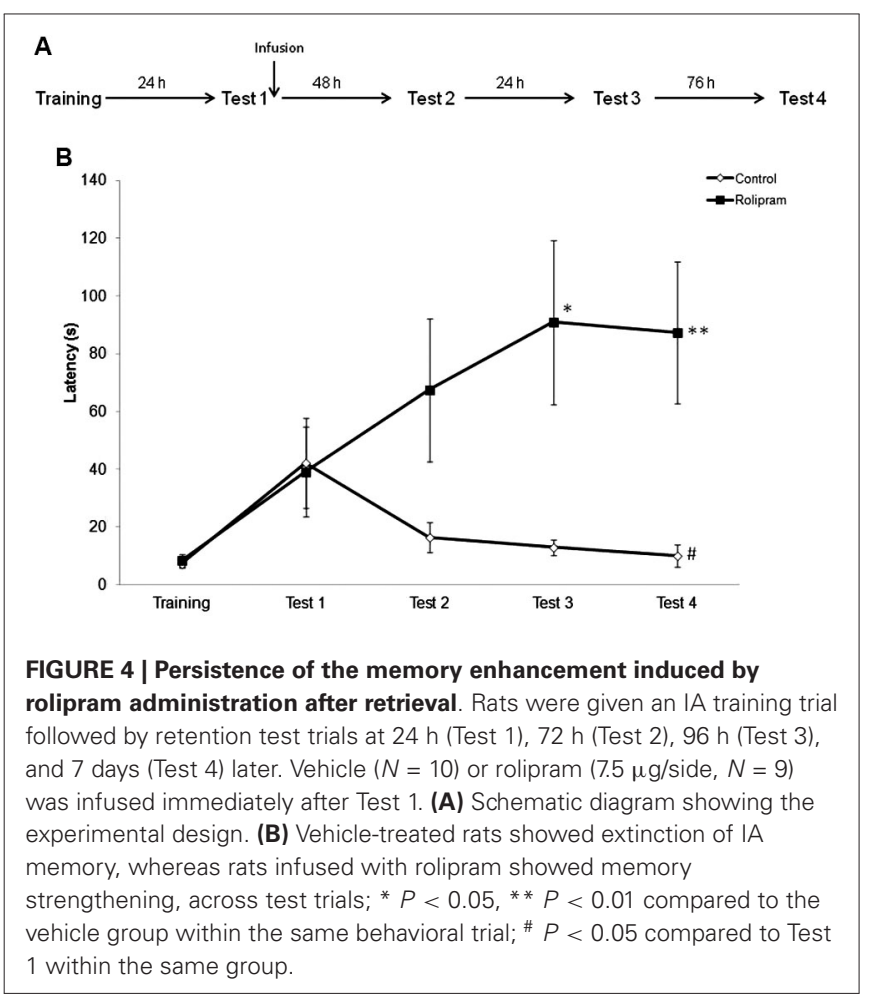

latencies across test trials (Friedman test, comparison across tests trials, $H=8.4, \mathrm{df}=3, P<0.05$ ) (Figure 4B). The results indicate that the enhancing effect of intrahippocampal rolipram given immediately after retrieval can last for at least 1 week. 


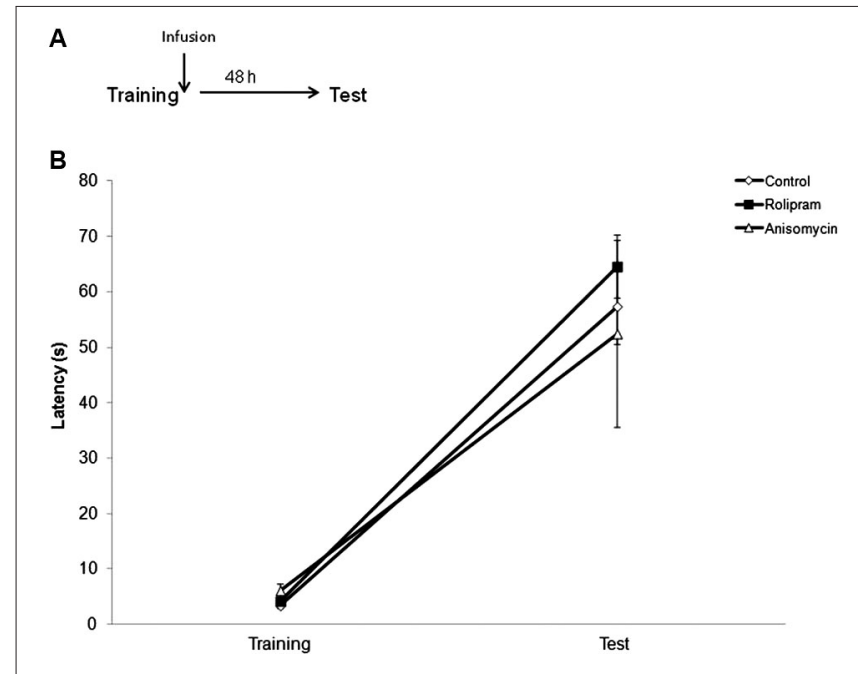

FIGURE 5 | Neither rolipram nor anisomycin affect IA memory formation when infused into the hippocampus immediately after training. Rats were given an IA training trial followed $48 \mathrm{~h}$ later by a test trial. An intrahippocampal infusion of vehicle $(N=11)$, rolipram $(7.5 \mu \mathrm{g} / \mathrm{side}$, $N=12)$ or anisomycin $(80.0 \mu \mathrm{g} / \mathrm{side}, N=9)$ was given immediately after training. (A) Schematic diagram showing the experimental design. (B) Latencies to step-down during IA behavioral trials. There were no significant differences among groups.

\section{ADMINISTRATION OF ROLIPRAM INTO THE HIPPOCAMPUS IMMEDIATELY AFTER TRAINING DOES NOT AFFECT MEMORY CONSOLIDATION}

In the last experiment, we verified whether rolipram and anisomycin could also affect IA memory consolidation. Vehicle $(N=$ $11)$, rolipram $(N=12)$ or anisomycin $(N=9)$ was infused into the hippocampus immediately after training, and retention was tested $48 \mathrm{~h}$ later. Results are shown in Figure 5. There were no differences between groups in Training (Kruskal Wallis test, Training, $H=3.8$, $\mathrm{df}=2, P=0.15$; Test, $H=4.2, \mathrm{df}=2, P=0.12$ ). The result suggests that neither rolipram nor anisomycin affected the consolidation phase of memory when given early after training.

\section{DISCUSSION}

Recall of a fear-motivated memory can lead to extinction, which likely involves the creation of a second memory trace that decreases fear expression (Quirk and Mueller, 2008). Alternatively, retrieval can induce the labilization of the original memory, which again becomes sensitive to interference, a process usually referred to as reconsolidation. It has been proposed that reconsolidation can serve to maintain, update, or alter the strength of memories (Sara, 2000a,b; Amaral et al., 2008; Lee, 2008, 2010; Alberini, 2011; Alberini and Ledoux, 2013; de Oliveira Alvares et al., 2013; Reichelt and Lee, 2013).

Several studies have shown that whether a retrieved memory will undergo extinction or reconsolidation depends on the conditions under which the memory is learned and reactivated, factors that are generally manipulated experimentally by altering the training intensity, retrieval session duration, or intervals between behavioral trials (Eisenberg et al., 2003; Pedreira and Maldonado,
2003; Suzuki et al., 2004; Lee et al., 2006; Inda et al., 2011; Flavell and Lee, 2013). Here, we show that, within an experimental condition that promotes extinction in control rats, inhibiting PDE4 in the dorsal hippocampus can alter the fate of the memory towards strengthening. Both extinction and rolipram-induced strengthening depend on protein synthesis, since infusion with anisomycin blocked both processes. Control experiments omitting the first retrieval trial or using delayed and posttraining infusions indicate that the effects were not due to long-lasting drug-induced alterations in locomotion, motivation, anxiety, sensory function, or other nonspecific factors. To our knowledge, this is the first direct demonstration of a pharmacologically-inducible "switch" between memory extinction and reconsolidation.

Although most studies on reconsolidation have focused on the disruption of recalled memories by administration of amnestic agents, there is previous evidence that some drug treatments can enhance retention when paired with retrieval. Early studies showed that systemic injections of strychnine after retrieval could enhance IA memory in rats (Gordon, 1977). More recently, memories for fear conditioning in rats have been shown to be enhanced by post-retrieval administration of drugs including the protein kinase A (PKA) activator 6-BNZ-cAMP infused into the basolateral amygdala (BLA; Tronson et al., 2006), the partial $\mathrm{N}$-methyl-D-aspartate (NMDA) receptor agonist D-cycloserine injected systemically (Lee et al., 2006), or the CB1 cannabinoid receptor antagonist AM251 infused into the dorsal hippocampus (de Oliveira Alvares et al., 2008). However, in all previous studies, the experimental conditions used were such that control rats did not show significant extinction across test trials.

Memory strengthening has been observed after either reinforced (i.e., with additional training) or non-reinforced (retrieval alone in the absence of a reinforcing stimulus) re-exposure to the learning context (Roesler et al., 1998, 2000; Quevedo et al., 1999; Lee, 2008; Roesler and Quevedo, 2009; Inda et al., 2011; Pedroso et al., 2013; Reichelt and Lee, 2013). Since strengthening depends critically on retrieval of the original memory (Roesler and Quevedo, 2009), and requires molecular mechanisms in the hippocampus that specifically underlie reconsolidation (Lee, 2008), is has been proposed that reconsolidation is the mechanism mediating strengthening (Lee, 2008; Alberini and Ledoux, 2013). Memory enhancement by repeated retrieval has been seen as a possible adaptive function of reconsolidation, since it allows relevant fear memories to be strengthened without requiring reexposure to the original aversive learning experience (Alberini and Ledoux, 2013). It should be noted, however, that our findings do not clearly allow us to exclude the possibility that mechanisms other than reconsolidation mediate memory strengthening. One argument against the possibility of reconsolidation in this case is the fact that the latencies of animals treated with rolipram combined with anisomycin were similar between Test 2 and Test 1 , suggesting that anisomycin selectively blocked the rolipraminduced enhancement without affecting the original memory. Thus, rolipram could be inducing a condition in which memory reinforcement occurs without labilization of the original memory (Osan et al., 2011; Pedroso et al., 2013). However, it should be noted that reconsolidation blockade with post-retrieval intrahippocampal anisomycin has not been consistently demonstrated in 
the step-down IA task (Vianna et al., 2001). Moreover, a slight trend for decreased latencies across the 3 test trials was observed in rats receiving rolipram and anisomycin, although this did not reach statistical significance. Thus, our data do not exclude the possibility that reconsolidation-like mechanisms are involved in the memory strengthening effect observed.

It has been hypothesized that high levels of attention or arousal during retrieval could reinforce the memory trace through endogenous mechanisms that might involve increased release of modulators such as catecholamines (Sara, 2000b). This possibility is consistent with the studies mentioned above showing that drugs that stimulate modulatory pathways can enhance memory when given shortly after retrieval. The findings reported by Tronson et al. (2006) showing strengthening of fear conditioning memory by a PKA activator after retrieval are particularly relevant for comparison with our present results, since PDE4 inhibitors such as rolipram enhance memory by increasing neuronal levels of cAMP, thus ultimately activating the cAMP/PKA/cAMP response-element binding protein (CREB) pathway (Barad et al., 1998; Bach et al., 1999; Bourtchouladze et al., 2003; Tully et al., 2003; Gong et al., 2004; de Lima et al., 2008). Further support for a crucial role of cAMP/PKA/CREB signaling in promoting memory strengthening upon retrieval has been provided by recent evidence that the experimentally-induced activation of amygdalar neurons expressing elevated CREB was sufficient to induce the recall of an established fear memory and promote a reconsolidation-like reorganization process leading to memory strengthening (Kim et al., 2014). The cAMP/PKA/CREB pathway is a particularly promising candidate mechanism regulating the fate of memories during retrieval, since it is crucially involved in memory formation and mediates the actions of many endogenous modulators of emotional memory, including dopamine and norepinephrine (Abel et al., 1997; Bevilaqua et al., 1997; Bach et al., 1999; Tully et al., 2003; Quevedo et al., 2004; Roesler and Schröder, 2011).

In previous studies using IA, we found that similar retrieval conditions could result in memory extinction (Luft et al., 2006), reconsolidation sensitive to impairment by mTOR inhibition (Jobim et al., 2012), or protein-synthesis dependent, retrievalinduced, memory strentgthening (Pedroso et al., 2013). However, the behavioral and neurochemical factors determining these different outcomes of retrieval remain elusive. According to the "trace dominance" model, the result of a retrieval session/extinction trial involves the sum of multiple and conflicting processes, including a competition between the original excitatory memory trace and a new inhibitory extinction trace, for the control of behavior (Eisenberg et al., 2003). More recent computational work has proposed that network dynamics can lead to strengthening without labilization, reconsolidation or extinction depending on the degree of mismatch between the original memory and the retrieval session (Osan et al., 2011). Nevertheless, the current results indicate that the definition of the dominant process during retrieval can be altered by pharmacological manipulation of the hippocampus.

The present findings indicate that PDE4 inhibition, presumably by enhancing cAMP signaling, can shift the balance between the processes occurring during retrieval, directing a recalled memory in a way that favors strengthening rather than extinction. In this sense, it is interesting to note that, in fear conditioning, some data suggest that hippocampal and prefrontal inputs converge on the amygdala, with the former driving fear expression and reconsolidation and the latter favoring extinction (Herry et al., 2008; Mamiya et al., 2009). It is possible that stimulating neuronal populations responsible for the representation of the fear memory in the hippocampus through manipulation of the AMPc/PKA/CREB cascade could shift this balance in favor of hippocampal inputs driving maintenance and strengthening of the original memory. This hypothesis should be further examined by future experiments.

Although both protein synthesis and PKA activity in the dorsal hippocampus are required for memory formation, we did not find effects of rolipram or anisomycin when infused after learning. However, previous reports have indicated that intra-hippocampal anisomycin can impair IA memory consolidation when given before or $3 \mathrm{~h}$ after, but not immediately after training (Quevedo et al., 1999). Also, drugs acting on the PKA pathway have been shown to influence IA memory consolidation only when infused into the hippocampus $3 \mathrm{~h}$ posttraining (Bevilaqua et al., 1997). Thus, the reason for the lack of effect of rolipram and anisomycin in this case is likely to be related to temporal factors, and does not imply that IA consolidation is independent from protein synthesis.

In conclusion, we provide evidence suggesting that the behavioral outcome of the recall of an established memory can be pharmacologically switched from extinction towards strengthening through a purely pharmacological intervention, by pairing retrieval with PDE4 inhibition in the dorsal hippocampus. These findings may contribute to our understanding of the factors governing memory modifications induced by recall.

\section{ACKNOWLEDGMENTS}

This research was supported by the National Council for Scientific and Technological Development (CNPq; grant numbers 400839/2005-9, 303703/2009-1 and 303276/2013-4 to Rafael Roesler), the National Institute for Translational Medicine (INCT-TM), and the South American Office for Anticancer Drug Development.

\section{REFERENCES}

Abel, T., Nguyen, P. V., Barad, M., Deuel, T. A., Kandel, E. R., and Bourtchouladze, R. (1997). Genetic demonstration of a role for PKA in the late phase of LTP and in hippocampus-based long-term memory. Cell 88, 615-626. doi: 10. 1016/s0092-8674(00)81904-2

Alberini, C. M. (2011). The role of reconsolidation and the dynamic process of long-term memory formation and storage. Front. Behav. Neurosci. 5:12. doi: 10. 3389/fnbeh.2011.00012

Alberini, C. M., and Ledoux, J. E. (2013). Memory reconsolidation. Curr. Biol. 23, R746-R750. doi: 10.1016/j.cub.2013.06.046

Amaral, O. B., Osan, R., Roesler, R., and Tort, A. B. (2008). A synaptic reinforcement-based model for transient amnesia following disruptions of memory consolidation and reconsolidation. Hippocampus 18, 584-601. doi: 10. 1002/hipo. 20420

Bach, M. E., Barad, M., Son, H., Zhuo, M., Lu, Y. F., Shih, R., et al. (1999). Agerelated defects in spatial memory are correlated with defects in the late phase of hippocampal long-term potentiation in vitro and are attenuated by drugs that enhance the cAMP signaling pathway. Proc. Natl. Acad. Sci. U S A 96, 5280-5285. doi: $10.1073 /$ pnas.96.9.5280 
Barad, M., Bourtchouladze, R., Winder, D. G., Golan, H., and Kandel, E. (1998). Rolipram, a type IV-specific phosphodiesterase inhibitor, facilitates the establishment of long-lasting long-term potentiation and improves memory. Proc. Natl. Acad. Sci. U S A 95, 15020-15025. doi: 10.1073/pnas.95.25. 15020

Bevilaqua, L., Ardenghi, P., Schröder, N., Bromberg, E., Schmitz, P. K., Schaeffer, E., et al. (1997). Drugs acting upon the cyclic adenosine monophosphate/protein kinase A signalling pathway modulate memory consolidation when given late after training into rat hippocampus but not amygdala. Behav. Pharmacol. 8, 331338. doi: 10.1097/00008877-199708000-00006

Bourtchouladze, R., Lidge, R., Catapano, R., Stanley, J., Gossweiler, S., Romashko, D., et al. (2003). A mouse model of Rubinstein-Taybi syndrome: defective longterm memory is ameliorated by inhibitors of phosphodiesterase 4. Proc. Natl. Acad. Sci. U S A 100, 10518-10522. doi: 10.1073/pnas.1834280100

Bouton, M. E., and Bolles, R. C. (1979). Role of conditioned contextual stimuli in reinstatement of extinguished fear. J. Exp. Psychol. Anim. Behav. Process. 5, 368378. doi: 10.1037/0097-7403.5.4.368

de Lima, M. N., Presti-Torres, J., Garcia, V. A., Guimarães, M. R., Scalco, F. S., Roesler, R., et al. (2008). Amelioration of recognition memory impairment associated with iron loading or aging by the type 4-specific phosphodiesterase inhibitor rolipram in rats. Neuropharmacology 55, 788-792. doi: 10.1016/j. neuropharm.2008.06.025

de Oliveira Alvares, L., Crestani, A. P., Cassinim, L. F., Haubrich, J., Santana, F., and Quillfeldt, J. A. (2013). Reactivation enables memory updating, precisionkeeping and strengthening: exploring the possible biological roles of reconsolidation. Neuroscience 244, 42-48. doi: 10.1016/j.neuroscience.2013.04.005

de Oliveira Alvares, L., Pasqualini Genro, B., Diehl, F., Molina, V. A., and Quillfeldt, J. A. (2008). Opposite action of hippocampal CB1 receptors in memory reconsolidation and extinction. Neuroscience 154, 1648-1655. doi: 10.1016/j. neuroscience.2008.05.005

Eisenberg, M., Kobilo, T., Berman, D. E., and Dudai, Y. (2003). Stability of retrieved memory: inverse correlation with trace dominance. Science 301, 1102-1104. doi: $10.1126 /$ science. 1086881

Flavell, C. R., and Lee, J. L. (2013). Reconsolidation and extinction of an appetitive pavlovian memory. Neurobiol. Learn. Mem. 104, 25-31. doi: 10.1016/j.nlm.2013. 04.009

Gong, B., Vitolo, O. V., Trinchese, F., Liu, S., Shelanski, M., and Arancio, O. (2004). Persistent improvement in synaptic and cognitive functions in an Alzheimer mouse model after rolipram treatment. J. Clin. Invest. 114, 1624-1634. doi: 10. $1172 /$ jci22831

Gordon, W. C. (1977). Susceptibility of a reactivated memory to the effects of strychnine: a time-dependent phenomenon. Physiol. Behav. 18, 95-99. doi: 10. 1016/0031-9384(77)90099-3

Herry, C., Ciocchi, S., Senn, V., Demmou, L., Muller, C., and Lüthi, A. (2008). Switching on and off fear by distinct neuronal circuits. Nature 454, 600-606. doi: $10.1038 /$ nature 07166

Inda, M. C., Muravieva, E. V., and Alberini, C. M. (2011). Memory retrieval and the passage of time: from reconsolidation and strengthening to extinction. $J$. Neurosci. 31, 1635-1643. doi: 10.1523/JNEUROSCI.4736-10.2011

Jobim, P. F., Pedroso, T. R., Christoff, R. R., Werenicz, A., Maurmann, N., Reolon, G. K., et al. (2012). Inhibition of mTOR by rapamycin in the amygdala or hippocampus impairs formation and reconsolidation of inhibitory avoidance memory. Neurobiol. Learn. Mem. 97, 105-112. doi: 10.1016/j.nlm.2011. 10.002

Kim, J., Kwon, J. T., Kim, H. S., Josselyn, S. A., and Han, J. H. (2014). Memory recall and modifications by activating neurons with elevated CREB. Nat. Neurosci. 17, 65-72. doi: 10.1038/nn.3592

Lee, J. L. (2008). Memory reconsolidation mediates the strengthening of memories by additional learning. Nat. Neurosci. 11, 1264-1266. doi: 10.1038/nn.2205

Lee, J. L. (2010). Memory reconsolidation mediates the updating of hippocampal memory content. Front. Behav. Neurosci. 4:168. doi: 10.3389/fnbeh.2010. 00168

Lee, J. L., Milton, A. L., and Everitt, B. J. (2006). Reconsolidation and extinction of conditioned fear: inhibition and potentiation. J. Neurosci. 26, 10051-10056. doi: 10.1523/jneurosci.2466-06.2006

Luft, T., Flores, D. G., Vianna, M. R., Schwartsmann, G., Roesler, R., and Izquierdo, I. (2006). A role for hippocampal gastrin-releasing peptide receptors in extinction of aversive memory. Neuroreport 17, 935-939. doi: 10.1097/01.wnr. 0000221832.33717 .48
Mamiya, N., Fukushima, H., Suzuki, A., Matsuyama, Z., Homma, S., Frankland, P. W., et al. (2009). Brain region-specific gene expression activation required for reconsolidation and extinction of contextual fear memory. J. Neurosci. 29, 402413. doi: 10.1523/JNEUROSCI.4639-08.2009

McGaugh, J. L. (2000). Memory: a century of consolidation. Science 287, 248-251. doi: $10.1126 /$ science.287.5451.248

Nader, K., Schafe, G. E., and Le Doux, J. E. (2000). Fear memories require protein synthesis in the amygdala for reconsolidation after retrieval. Nature 406, 722 726. doi: $10.1038 / 35021052$

Osan, R., Tort, A. B. L., and Amaral, O. B. (2011). A mismatch-based model for memory reconsolidation and extinction in attractor networks. PLoS One 6:e23113. doi: 10.1371/journal.pone.0023113

Paxinos, G., and Watson, C. (2007). The Rat Brain in Stereotaxic Coordinates. 6th Edn. San Diego: Academic Press.

Pedreira, M. E., and Maldonado, H. (2003). Protein synthesis subserves reconsolidation or extinction depending on reminder duration. Neuron 38, 863-869. doi: 10.1016/s0896-6273(03)00352-0

Pedroso, T. R., Jobim, P. F., Carvalho, L. M., Christoff, R. R., Maurmann, N., Reolon, G. K., et al. (2013). Inhibition of protein synthesis or mTOR in the basolateral amygdala blocks retrieval-induced memory strengthening. J. Neural Transm. 120, 1525-1531. doi: 10.1007/s00702-013-1032-y

Quevedo, J., Vianna, M. R., Martins, M. R., Barichello, T., Medina, J. H., Roesler, R., et al. (2004). Protein synthesis, PKA, and MAP kinase are differentially involved in short- and long-term memory in rats. Behav. Brain Res. 154, 339-343. doi: 10. 1016/j.bbr.2004.03.001

Quevedo, J., Vianna, M. R., Roesler, R., de-Paris, F., Izquierdo, I., and Rose, S. P. (1999). Two time windows of anisomycin-induced amnesia for inhibitory avoidance training in rats: protection from amnesia by pretraining but not preexposure to the task apparatus. Learn. Mem. 6, 600-607. doi: 10.1101/lm.6. 6.600

Quirk, G. J., and Mueller, D. (2008). Neural mechanisms of extinction learning and retrieval. Neuropsychopharmacology 33, 56-72. doi: 10.1038/sj.npp.130 1555

Reichelt, A. C., and Lee, J. L. (2013). Memory reconsolidation in aversive and appetitive settings. Front. Behav. Neurosci. 7:118. doi: 10.3389/fnbeh.2013. 00118

Roesler, R., and Quevedo, J. (2009). Retrieval mediated by hippocampal extracellular signal-regulated kinase/mitogen-activated protein kinase is required for memory strengthening. Neuroscience 160, 711-715. doi: 10.1016/j.neuroscience. 2009.03.024

Roesler, R., and Schröder, N. (2011). Cognitive enhancers: focus on modulatory signaling influencing memory consolidation. Pharmacol. Biochem. Behav. 99, 155-163. doi: 10.1016/j.pbb.2010.12.028

Roesler, R., Luft, T., Oliveira, S. H., Farias, C. B., Almeida, V. R., Quevedo, J., et al. (2006). Molecular mechanisms mediating gastrin-releasing peptide receptor modulation of memory consolidation in the hippocampus. Neuropharmacology 51, 350-357. doi: 10.1016/j.neuropharm.2006.03.033

Roesler, R., Valvassori, S. S., Castro, A. A., Luft, T., Schwartsmann, G., and Quevedo, J. (2009). Phosphoinositide 3-kinase is required for bombesin-induced enhancement of fear memory consolidation in the hippocampus. Peptides 30, 1192 1196. doi: 10.1016/j.peptides.2009.02.007

Roesler, R., Vianna, M. R., de-Paris, F., Rodrigues, C., Sant'Anna, M. K., Quevedo, J., et al. (2000). NMDA receptor antagonism in the basolateral amygdala blocks enhancement of inhibitory avoidance learning in previously trained rats. Behav. Brain Res. 112, 99-105. doi: 10.1016/s0166-4328(00) 00169-8

Roesler, R., Vianna, M., Sant'Anna, M. K., Kuyven, C. R., Kruel, A. V., Quevedo, J., et al. (1998). Intrahippocampal infusion of the NMDA receptor antagonist AP5 impairs retention of an inhibitory avoidance task: protection from impairment by pretraining or preexposure to the task apparatus. Neurobiol. Learn. Mem. 69, 87-91. doi: 10.1006/nlme.1997.3810

Sara, S. J. (2000a). Retrieval and reconsolidation: toward a neurobiology of remembering. Learn. Mem. 7, 73-84. doi: 10.1101/lm.7.2.73

Sara, S. J. (2000b). Strengthening the shaky trace through retrieval. Nat. Rev. Neurosci. 1, 212-213. doi: 10.1038/35044575

Suzuki, A., Josselyn, S. A., Frankland, P. W., Masushige, S., Silva, A. J., and Kida, S. (2004). Memory reconsolidation and extinction have distinct temporal and biochemical signatures. J. Neurosci. 24, 4787-4795. doi: 10.1523/jneurosci.549103.2004 
Tronel, S., and Alberini, C. M. (2007). Persistent disruption of a traumatic memory by postretrieval inactivation of glucocorticoid receptors in the amygdala. Biol. Psychiatry 62, 33-39. doi: 10.1016/j.biopsych.2006.09.009

Tronson, N. C., Wiseman, S. L., Olausson, P., and Taylor, J. R. (2006). Bidirectional behavioral plasticity of memory reconsolidation depends on amygdalar protein kinase A. Nat. Neurosci. 9, 167-169. doi: 10.1038/nn1628

Tully, T., Bourtchouladze, R., Scott, R., and Tallman, J. (2003). Targeting the CREB pathway for memory enhancers. Nat. Rev. Drug Discov. 2, 267-277. doi: 10. 1038/nrd1061

Vianna, M. R., Szapiro, G., McGaugh, J. L., Medina, J. H., and Izquierdo, I. (2001). Retrieval of memory for fear-motivated training initiates extinction requiring protein synthesis in the rat hippocampus. Proc. Natl. Acad. Sci. U S A 98, 1225112254. doi: 10.1073/pnas.211433298

Werenicz, A., Christoff, R. R., Blank, M., Jobim, P. F., Pedroso, T. R., Reolon, G. K., et al. (2012). Administration of the phosphodiesterase type 4 inhibitor rolipram into the amygdala at a specific time interval after learning increases recognition memory persistence. Learn. Mem. 19, 495-498. doi: 10.1101/lm.026 997.112
Conflict of Interest Statement: The authors declare that the research was conducted in the absence of any commercial or financial relationships that could be construed as a potential conflict of interest.

Received: 10 January 2014; paper pending published: 30 January 2014; accepted: 02 March 2014; published online: 17 March 2014.

Citation: Roesler R, Reolon GK, Maurmann N, Schwartsmann G, Schröder N, Amaral $O B$, Valvassori $S$ and Quevedo J (2014) A phosphodiesterase 4-controlled switch between memory extinction and strengthening in the hippocampus. Front. Behav. Neurosci. 8:91. doi: 10.3389/fnbeh.2014.00091

This article was submitted to the journal Frontiers in Behavioral Neuroscience. Copyright (c) 2014 Roesler, Reolon, Maurmann, Schwartsmann, Schröder, Amaral, Valvassori and Quevedo. This is an open-access article distributed under the terms of the Creative Commons Attribution License (CC BY). The use, distribution or reproduction in other forums is permitted, provided the original author(s) or licensor are credited and that the original publication in this journal is cited, in accordance with accepted academic practice. No use, distribution or reproduction is permitted which does not comply with these terms. 